\title{
A Model to Enhance Overall Well-Being, Mental Health Practices and Professional Development Among Division III Student-Athletes as They Transition from Athlete to Professional
}

\author{
JoAnne Bullard \\ Rowan University
}

Bob Bullard

Rowan University

Sean Hendricks

Rowan University

\author{
Dave Naphy \\ Rowan University
}

\begin{abstract}
PROF Academy served as a model for Division III institutions to assist student-athletes as they transition into the professional environment by providing education on mental health and career development concepts such as mindfulness, stress management, anxiety, résumé writing, interviewing skills, and networking. This pilot program enhanced interdisciplinary collaboration throughout Rowan University departments and improved the psychosocial well-being and career preparedness of student-athletes. Student-athletes were assessed utilizing a demographic questionnaire, as well as the National Collegiate Athletic Association Mental Health Best Practices anxiety screening tool and depression screening tool. Each were administered three times throughout the program: during the spring semester, the fall semester, and the conclusion of the program in the winter. The subject size for participants that completed all questionnaires in their entirety was $(N=14)$. Findings showed improvements among career preparedness constructs; reductions in depression constructs including poor appetite and self-blame; increases in difficulty sleeping; and reductions in anxiety constructs including feeling unsteady, numbness, fear of losing control, and difficulty breathing. This program served as a model that is readily replicable and scalable with its established modules and curriculum by other Division III institutions' athletic departments, especially since there is little implementation cost when institutions promote the use of their existing campus resources. It is the intent that PROF Academy will be provided to expand these modules throughout all four years of each student-athlete's experience at Rowan University.
\end{abstract}

Keywords: student-athlete well-being, student-athlete professional development, studentathlete mental health, student-athlete transition 


\section{Inception of the Program Model}

The goal of this project was to create an impactful program, entitled "PROF Academy," to assist Division III college student-athletes as they transition into the professional environment by providing education on mental health and overall well-being concepts, such as mindfulness, stress management, anxiety reduction techniques, and understanding of depression. PROF Academy consisted of workshops and online modules that addressed the above topics, as well as career development skills, résumé and cover letter writing, interviewing skills, and networking. This innovative program was designed to enhance interdisciplinary collaboration among a National Collegiate Athletic Association (NCAA) Division III campus to holistically bolster the psychosocial well-being and mental health of student-athletes. Rowan University, a Division III, New Jersey Athletic Conference (NJAC) institution, identified a strong need for PROF Academy to enhance the well-being and development of student-athletes in three major phases: while attending college, preparing for the transition out of college into future careers, and continuing education opportunities. Upon review of each of the NJAC's member institutions, no such program was found to have been implemented.

PROF Academy, named after Rowan University's mascot "The Prof," served as a model for these institutions to enhance awareness of student-athlete needs and their overall well-being as they transition from a student-athlete to a professional. This program provided a way to not only enhance the learning experience and collaborative efforts of departments among the campus, but also delivered an innovative way for student-athletes to enhance their self-care and well-being. Additionally, it allowed for the athletic administration to understand the specific needs that the student-athletes presented. Becoming aware of these needs would then serve as a way to develop programs effectively for student-athletes during their time at the institution.

\section{Literature Review}

Stroll (1995) posits that Division III student-athletes are not afforded the scholarships and media attention that Division I student-athletes often enjoy, thus, the former experience a different college experience with perhaps a greater focus on academics. As academic performance and demands are stressors to student-athletes transitioning from high school to college, it is imperative that this is addressed proactively to provide a safe environment in the college setting (Hoover, 2012; Kroshus, 2015). While adjusting to a new environment, college students-athletes may experience changes in their relationships, financial management, and sleep habits (Davoren \& Hwang, 2014; Kroshus, 2015, p. 236). In addition, Comeaux and Harrison (2011) stated that student-athletes devote over " 40 hours each week on sport related activities, including mental fatigue and physical exhaustion." This commitment, in addition to demands outside of sport, can be a great deal for any student-athlete to manage. 
Along with these changes, many student-athletes experience anxiety and depression on higher levels than usual as compared to nonathletes, which could be related to several factors, i.e., academic problems (Born, 2017; Davoren \& Hwang, 2014; Ryan et al., 2018). Davoren and Hwang (2014) reported that over the period of one year, 30\% of 195,000 college students reported feeling depressed, and 50\% reported feeling anxious. Transitioning to college may also increase the risk of potential alcohol abuse, injuries, and negative behaviors (Chew \& Thompson, 2014). In addition, there is elevated likelihood of comorbidity of mental health disorders, e.g., if an individual presents with one illness, such as depression, he or she might also have a higher likelihood of abusing alcohol (Kroshus, 2016).

The number of student-athletes who experience mental health issues is rising each year (NCAA GOALS, 2016). According to Born (2017), compared to the general population of college students, student-athletes are more likely to experience mental illnesses. In addition, there has been an increase since last year in the number of student-athletes feeling overwhelmed (NCAA GOALS, 2016). Some student-athletes may actively utilize mental health services on campus, while others may not use them or know they are present on campus. According to Born (2017), it is estimated that between $10-15 \%$ of student-athletes experience mental health issues that would benefit from counseling measures. This is also a higher percentage than the general population of college students.

As reported in the NCAA 2016 GOALS data, a little less than half of the student-athlete population that utilized mental health services were satisfied with the care they received. Overall, it is found that student-athletes are not very likely to seek professional help when in need and are not likely to utilize the mental health resources on campus (Born, 2017; Ryan et al., 2018). Kroshus (2016) identified the importance of providing early identification and treatment of mental health disorders. Through providing opportunities for prevention, student-athletes could benefit from harm reduction and reduce the burden they experience (Kroshus, 2016). Many Division III studentathletes have the aspiration to graduate from college and either enter the workforce or attend graduate school (NCAA GOALS, 2016). Hoover (2012) indicated that Division III student-athletes transition in their late junior year/early senior year, shifting focus from athletics to their potential careers. While student-athletes believe that their athletic experience will help them develop skills that will be helpful in future careers, resuls from this study indicate they have difficulties finding experiential learning opportunities due to the time constraints of their dual roles.

In addition, it is important to understand the needs of student-athletes to guide their successful trajectories from college to their careers. Per the student-athlete responses from the NCAA 2016 GOALS Study, the most-requested responses regarding what they wanted to receive from administrators and/or coaches were "academic success especially preparing to get a job after college" and learning how to balance both athletics and academics positively (p. 129). According to Bell et al. (2018), there is a lack of research conducted on Division II and Division III levels, since most of the research regarding career exploration and engagement for student-athletes has been focused on the Division I level, which represents approximately 37\% of all student-athletes. With the demands student-athletes are exposed to, it could be challenging for them to dedicate the time and commitment towards exploring future careers and working on career preparedness techniques. This includes the lack of opportunity to evaluate individual needs, values, and interests, which is also known as identity development (Lally \& Kerr, 2005). The role commitments of being 
a student-athlete could potentially take them away from developing a strong identity during their time in college and could negatively impact them for their future, resulting in poor attitudes and underemployment (Bell et al., 2018; Lally \& Kerr, 2005).

\section{Conceptual Framework}

The PROF Academy model was a workshop and online series that included components of student-athlete well-being, enhancement of mental health, and professional development delivered to student-athletes at Rowan University. All junior student-athletes were invited to participate in a series of modules, both face-to-face and in an online Blackboard Learning Management System course shell. Outreach was conducted through coaches and athletic administration to encourage student-athletes to participate in Prof Academy. These modules addressed components beneficial to student-athletes in preparing to enter the professional environment.

The modules included:

(a) Mindfulness: Enhancing Self-Awareness

(b) Credentialing for the Future: Résumé Writing, Cover Letter Writing, and Navigating the Job Search

(c) Improving Interviewing Skills through Mock Interviews

(d) Stress Management Techniques

(e) Understanding Anxiety and Depression

(f) Addressing Student-Athlete Needs

(g) Increasing Awareness of Mental Health Services on Campus

(h) Networking

PROF Academy was implemented during the spring and fall 2017 semesters. Each monthly module addressed a specific topic and included a speaker from the Rowan community. This enhanced the interdisciplinary approach to the program with professionals from the Offices of Career Advancement, Student Affairs and its Wellness Center, and faculty members from Rowan's Departments of Psychology and Health \& Exercise Science. In addition, supplemental materials and assignments were provided in the online Blackboard shell. The design for the Blackboard shell, developed by the creators of this program, included specific modules that each studentathlete in PROF Academy needed to complete in order to graduate from the program, which ensured their active engagement and participation. Some examples of career development the student-athletes were required to complete included uploading their résumés to receive feedback from the Office of Career Advancement or providing a self-reflection in response to the specific module concept. This online shell was a place for self-reflection, application of material, and an opportunity to receive feedback from Rowan University faculty and staff who were actively involved in this program.

The interdisciplinary collaboration among various administrative and academic departments for this project has been paramount in this holistic approach to bolstering the academic and professional success of student-athletes, while promoting their psychosocial wellbeing and wellness. On-campus collaboration included the Office of Career Advancement, 
University Advising Services, The Wellness Center, Office of Academic Transition \& Support Programs, the Athletics Department, the Psychology Department, the Health \& Exercise Science Department and the Office of Alumni Relations. Each constituent was asked to contribute by either hosting a session, providing supplemental material for the Blackboard shell, or providing their services to the student-athletes. Such a paradigm serves as an effective means to promote the awareness and use of these beneficial services and resources.

PROF Academy's culminating event was a student-athlete alumni-networking reception where former successful student-athletes who had either attended graduate school or worked in the professional environment were invited to share their experiences with those who had fulfilled the requirements of PROF Academy. This networking night proved to be a success and a valuable component of the program, not just for the participants, but also for alumni of the university. The student-athletes received a certificate for successfully completing the program. In addition, the successful completion of this program was recorded in their co-curricular transcript.

\section{Methodology}

During the spring 2017 semester, academic junior year student-athletes were contacted via email and invited to attend an informational session regarding this research study. This population of student-athletes was selected because they were beginning their transions from student-athlete to professionals. The pilot population included 39 academic junior year student-athletes. This population total reduced to 28 student-athletes after returning to school from summer break in the fall 2017 semester. There were 14 student-athletes to complete the program in its entirety, as well as all three questionnaire distributions. The relevant data/research guiding the program included student-athlete feedback in the 2016 NCAA Growth, Opportunities, Aspirations, and Learning of Students in College (GOALS) Study of the Student Athlete Experience. This model provided components for academic success, job preparedness, strategies on how to balance athletics and academics, along with enhancements of overall performance both in the classroom and in athletics.

To measure mental health factors, including anxiety and depression, the NCAA Sport Science Institute screening tools were utilized three times throughout the academic school year at the beginning of the program, at the half way point, and at the completion of the program. In addition, a preliminary questionnaire was provided to assess: gender, sport, major, GPA, résumé completion status, internship status, job status, and job interview experience. Programmatic outcomes were evaluated in both the short-term and the long-term. Depression and anxiety screening scales and assessment of professional development (e.g., secured internships, job placement status, and status of applying or being accepted into graduate school) were measured half-way through the program and at program completion.

Data analysis methods included T-tests, correlations, and ANOVA tests. It is important to note that only 17 student-athletes completed PROF Academy and of them, 14 student-athletes completed all three questionnaires. The following are findings based on the same questionnaire student-athletes received in Data Collection \#1 $(n=39)$, Data Collection \#2 $(n=28)$, and Data Collection \#3 $(n=17)$, as well as the 14 student-athletes that completed the program in its entirety and all questionnaires. 


\section{Findings}

Key findings were applied in a practical environment in the educational setting since this program model assessed the needs of student-athletes and matched them with available services already established on the Rowan University campus. Examples included: mental health services on campus, support from coaches and athletic administration, guidance from both the Office of Career Advancement and the Office of Academic Transition and Support Programs, and collaboration with the Psychology Department.

\section{Career Preparedness}

Based on the student-athletes that participated in this study, there was a steady increase among each of the survey collections regarding data including visiting the Rowan University Career Center, having a working résumé, stating that they had a job, stating that they had an internship, and stating that they had a job interview. The data in Table 1 and Table 2 indicate that student-athletes involved in the PROF Academy program were successful in completing their résumés, taking part in interviews, and using the Rowan University Office of Career Advancement as a resource on campus.

\section{Table 1}

Use of Career Advancement and Job Preparedness Services

\begin{tabular}{|cccc|}
\hline & $\begin{array}{c}\text { Data Collection \#1 } \\
(\mathbf{n = 3 9})\end{array}$ & $\begin{array}{c}\text { Data Collection \#2 } \\
(\mathbf{n = 2 8})\end{array}$ & $\begin{array}{c}\text { Data Collection \#3 } \\
(\mathbf{n = 1 7})\end{array}$ \\
\hline $\begin{array}{c}\text { Visited Rowan University } \\
\text { Office of Career } \\
\text { Advancement }\end{array}$ & $7(16.7 \%)$ & $8(28.6 \%)$ & $10(58.8 \%)$ \\
Had Working Résumé & $30(71.4 \%)$ & $23(82.1 \%)$ & $17(100 \%)$ \\
Had Job & $39(100 \%)$ & $28(100 \%)$ & $17(100 \%)$ \\
Had Internship & $15(35.7 \%)$ & $13(46.4 \%)$ & $17(100 \%)$ \\
Had Job Interview & $31(73.8 \%)$ & $24(85.7 \%)$ & \\
\hline
\end{tabular}

Note. Student-athlete data referring to use of Office of Career Advancement services and job preparedness among the three survey distributions. 


\section{Table 2}

Use of Career Advancement and Job Preparedness Services for Student-Athletes Who Completed Entire Program

\begin{tabular}{|c|c|c|c|}
\hline & $\begin{array}{c}\text { Data Collection \#1 } \\
(\mathbf{N = 1 4})\end{array}$ & $\begin{array}{c}\text { Data Collection \#2 } \\
(\mathbf{N = 1 4})\end{array}$ & $\begin{array}{c}\text { Data Collection \#3 } \\
(\mathbf{N = 1 4 )}\end{array}$ \\
\hline $\begin{array}{c}\text { Visited Rowan } \\
\text { University Office of } \\
\text { Career Advancement }\end{array}$ & $5(35.7 \%)$ & $5(35.7 \%)$ & $9(64.2 \%)$ \\
\hline Had Working Résumé & $11(78.5 \%)$ & $11(78.5 \%)$ & $14(100 \%)$ \\
\hline Had Job & $14(100 \%)$ & $14(100 \%)$ & $14(100 \%)$ \\
\hline Had Internship & $6(42.8 \%)$ & $7(50 \%)$ & $7(50 \%)$ \\
\hline Had Job Interview & $12(85.7 \%)$ & $13(92.8 \%)$ & $14(100 \%)$ \\
\hline
\end{tabular}

Note. Data referring to the use of Office of Career Advancement services and job preparedness among the three survey distributions and completion of the program of student-athletes that completed the program in its entirety.

\section{Anxiety and Depression}

The NCAA Mental Health Best Practices anxiety screening tool and depression screening tool were utilized as part of the assessments. The findings from Table 3 and Table 4 showed that the majority of student-athlete participants identified as having low levels of depression and low levels of anxiety throughout all three of our data collections. It was important to consider the individual questions to learn more about the needs of our student-athletes. Although the numbers might appear to be on the lower end, it still shown that there is a need for some form of programming or intervention that should be implemented on a consistent basis to assist our student-athletes. 
Table 3

Low Scoring Levels of Depression and Anxiety Screening Scales

\begin{tabular}{|l|c|c|c|}
\hline & $\begin{array}{c}\text { Data Collection \#1 } \\
(\mathbf{n = 3 9})\end{array}$ & $\begin{array}{c}\text { Data Collection\#2 } \\
(\mathbf{n = 2 8 +})\end{array}$ & $\begin{array}{c}\text { Data Collection \#3 } \\
(\mathbf{n = 1 7})\end{array}$ \\
\hline Low Levels of Depression & $69 \%$ & $96 \%$ & $94 \%$ \\
\hline Low Levels of Anxiety & $85.7 \%$ & $96 \%$ & $94 \%$ \\
\hline
\end{tabular}

Note. Student-athlete data referring to low scoring levels of both the depression screening scale and anxiety screening scale.

\section{Table 4}

Low Scoring Levels of Depression and Anxiety Screening Scales for Completion of Program

\begin{tabular}{|l|c|c|c|}
\hline & $\begin{array}{c}\text { Data Collection \#1 } \\
(\boldsymbol{N = 1 4 )}\end{array}$ & $\begin{array}{c}\text { Data Collection 2 } \\
(\boldsymbol{N = 1 4 )}\end{array}$ & $\begin{array}{c}\text { Data Collection \#3 } \\
(\boldsymbol{N = 1 4 )})\end{array}$ \\
\hline Low Levels of Depression & $78.5 \%$ & $100 \%$ & $92.8 \%$ \\
\hline Low Levels of Anxiety & $92.8 \%$ & $92.8 \%$ & $92.8 \%$ \\
\hline
\end{tabular}

Note: Student-athlete data referring to low scoring levels of both the depression screening scale and anxiety screening scale among those who successfully completed the program.

\section{Depression Constructs}

Figure 1 refers to the three data collections of student-athletes participating for any length of time in the program $(n=39 ; n=28 ; n=17)$. Figure 2 refers to the three data collections of studentathletes who completed the program in its entirety $(N=14)$. As shown in Figure 1, the depression constructs with the greatest reductions from Data Collection \#1 to Data Collection \#2 included self-blame, poor appetite, and thoughts of suicide. There were a few constructs where the percentages were reduced from Data Collection \#1 to Data Collection \#2, but the percentage then increased in Data Collection \#3. These constructs included low energy, worthlessness, no interest, hopeless for the future, and feeling blue. The difficulty concentrating construct responses decreased from Data Collection \#1 to Data Collection \#2 and then ended up increasing to the same percentage of Data Collection \#1 during the $3^{\text {rd }}$ data collection. The only construct that appeared to have a higher percentage in Data Collection \#3 as compared to the other two months was difficulty sleeping. 


\section{Figure 1}

Student-athlete Depression Screening "Some of the Time” Results Among the Three Questionnaire Distribution Periods

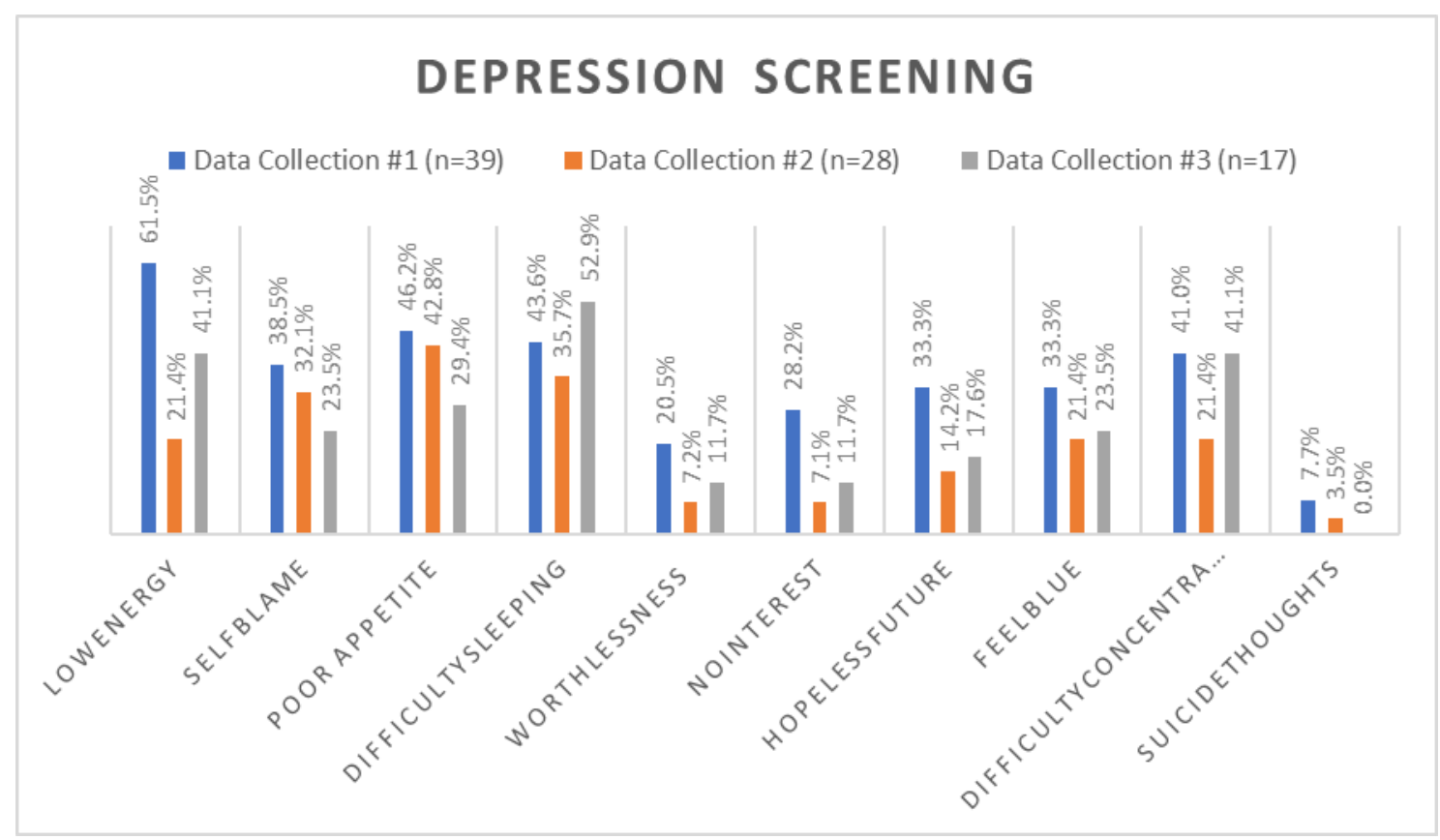

As shown in Figure 2, the depression constructs with the greatest reductions from Data Collection \#1 to Data Collection \#3 are poor appetite and self-blame. The depression constructs with reductions from Data Collection \#1 to Data Collection \#2 followed by an increase in Data Collection \#3 included having low energy, feeling worthless, having no interest, feeling hopeless for the future, feeling blue, and difficulty concentrating. Having suicidal thoughts remained at 0 throughout all three data collection points. The only construct with an increase from Data Collection \#1 to Data Collection \#3 was difficulty sleeping, comparable to Figure 1. Again, although these percentages may not categorize student-athletes having high levels of depression, these individual questions do show that there are higher percentages than what shows on an overall level. 


\section{Figure 2}

Depression Screening "Some of the Time” Results Among the Three Questionnaire Distribution Periods of Student-athletes Who Completed the Program in its Entirety

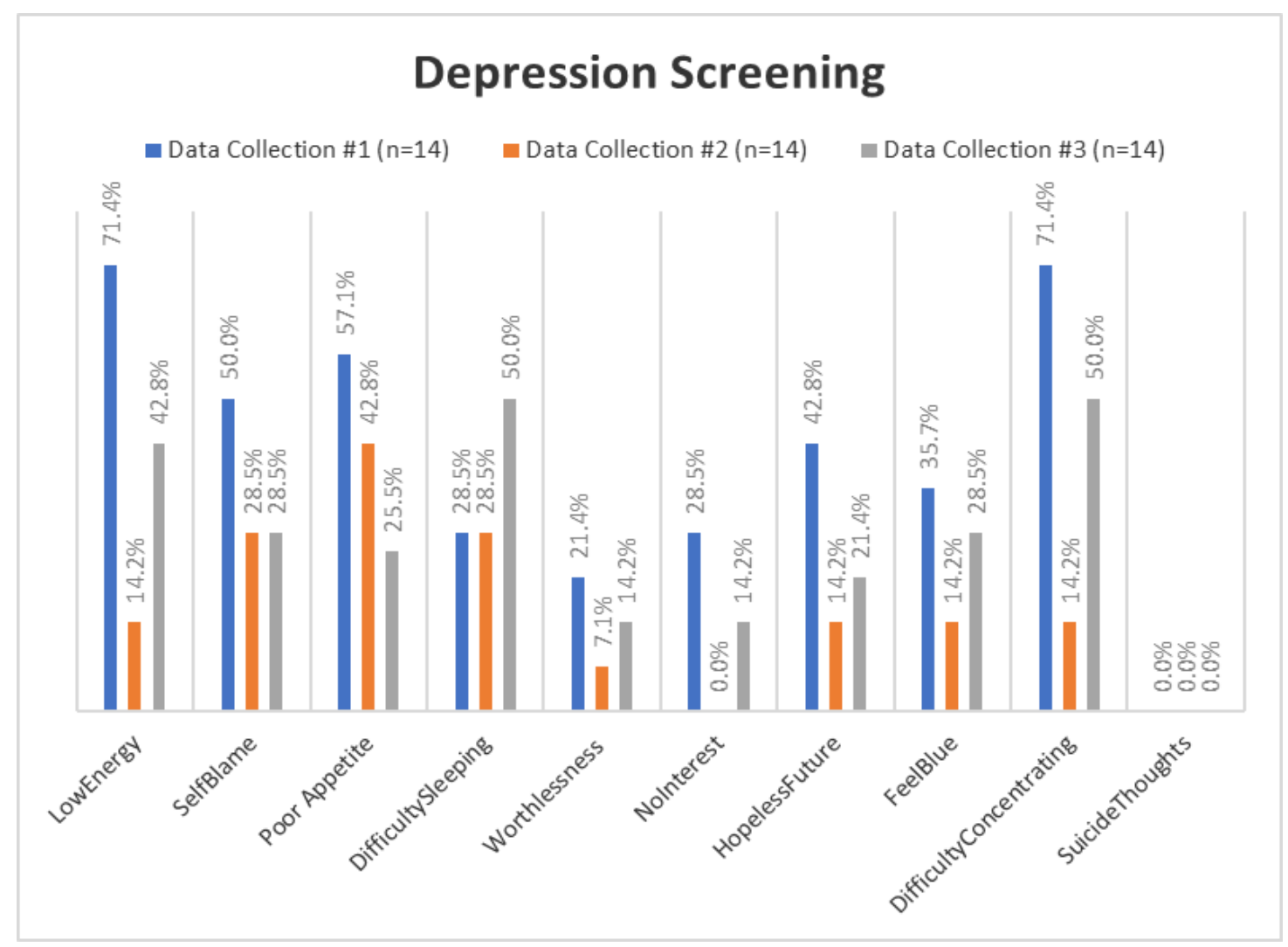

\section{Anxiety Constructs}

It was also important to examine the individual questions from the anxiety screening scale. Figure 3 refers to the three data collections of student-athletes participating for any length of time in the program $(n=39 ; n=28 ; n=17)$. Figure 4 refers to the three data collections of student-athletes that completed the program in its entirety $(N=14)$. Of the 21 questions asked, there were five in which responses raised attention, since percentages of mildly and moderate were elevated as compared to the other questions during the initial assessment during Data Collection \#1 (shown in Figure 3). These constructs included being unable to relax, fear of the worst, being terrified/afraid, being nervous, and being scared. Figure 3 depicts the "mildly" response of student-athletes that participated for any length of time in the program regarding the following anxiety constructs. There was a decrease among the three questionnaires, from Data Collection \#1 to Data Collection \#3, regarding being terrified and afraid and being scared. From Data Collection \#1 to Data Collection \#2, there was a decrease in percentage and then an increase in percentage in Data Collection \#3 regarding being unable to relax, fearing the worst, and being nervous. 


\section{Figure 3}

Student-athlete Anxiety Screening Scale “Mildly” Results Among the Three Questionnaire Distribution Periods

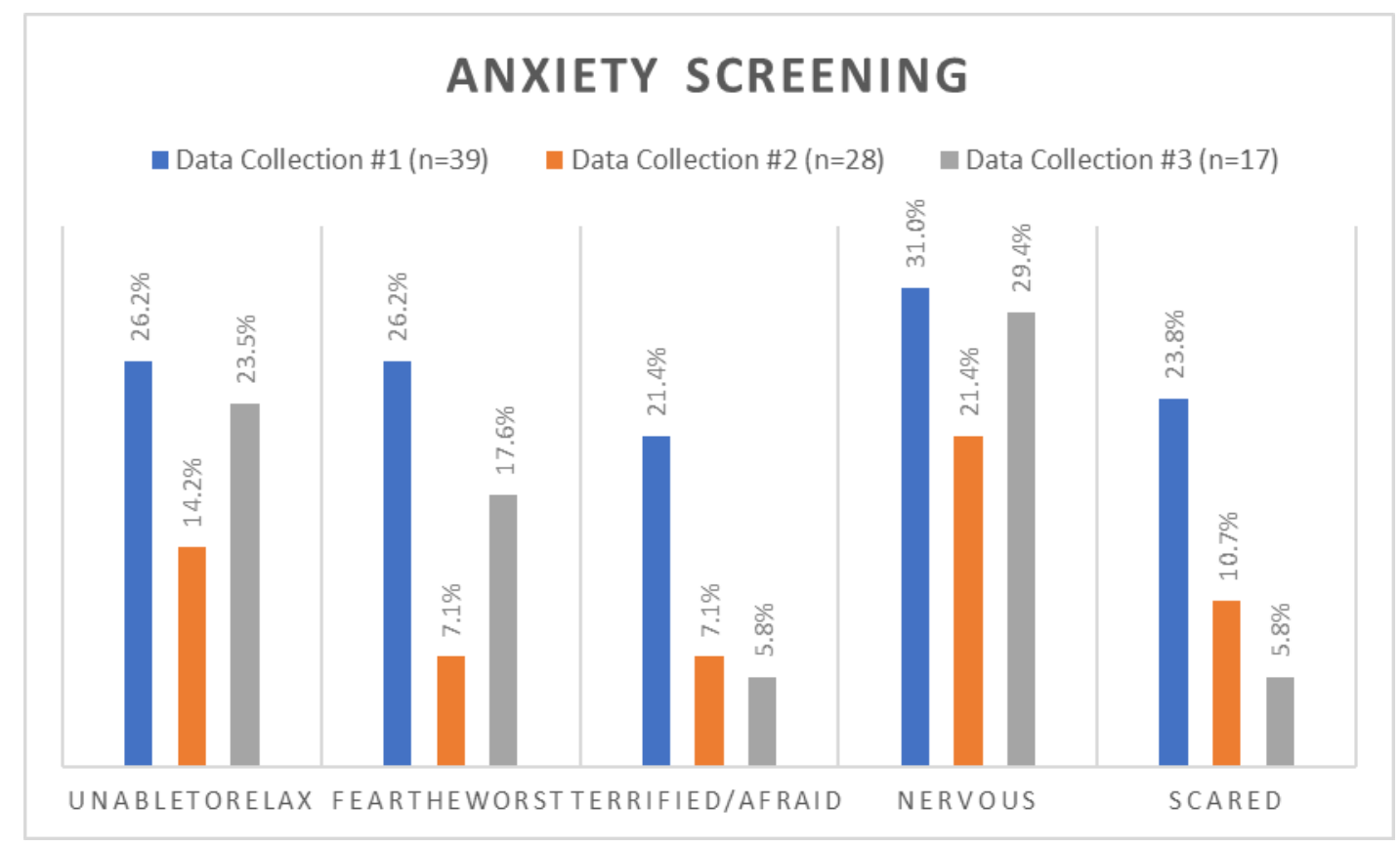

Figure 4 depicts the "mildly" response of student-athletes that completed the program in its entirety regarding the following anxiety constructs. Of the 14 student-athletes who successfully completed the program and all questionnaires, the anxiety constructs with the greatest reductions from Data Collection \#1 to Data Collection \#3 included numbness, feeling hot, feeling dizzy, pounding heart, feeling unsteady, being terrified, having trembling hands, feeling shaky, fearing losing control, difficulty breathing, feeling scared, feeling faint, and feeling flushed. There were a few anxiety constructs that decreased from Data Collection \#1 to Data Collection \#2 and then increased in Data Collection \#3. These included being unable to relax, fearing the worst, being nervous, having indigestion, and having hot/cold sweats. 


\section{Figure 4}

Student-athlete Anxiety Screening Scale "Mildly" Results Among the Three Questionnaire Distribution Periods for Those Who Successfully Completed the Program.

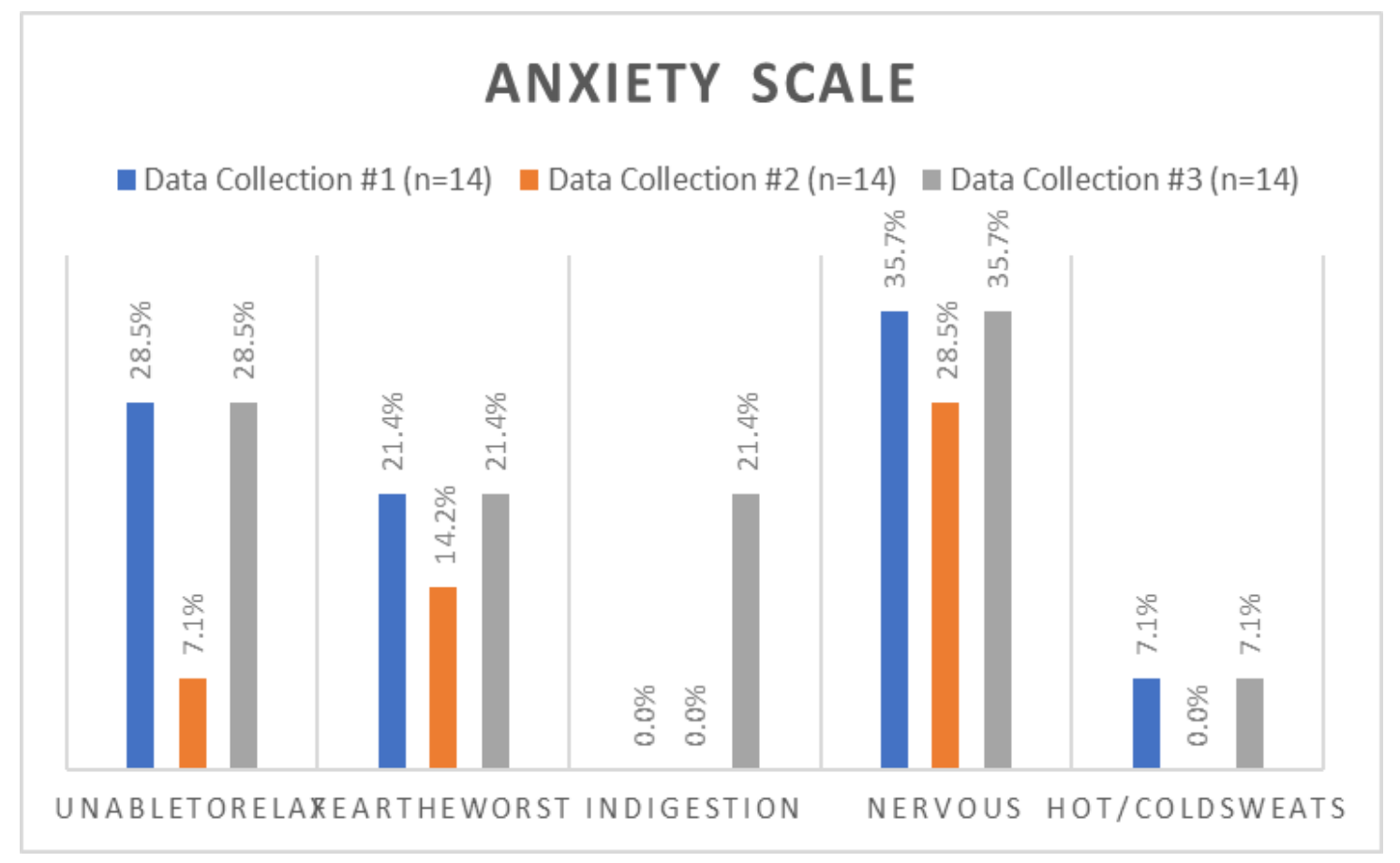

Again, the overall anxiety scores were considered to be low, but it was valuable to review the responses to each question so we can better understand the needs and concerns of our studentathletes.

\section{Discussion}

The findings from this program model proved that there were successes in reducing total depression screening scores, reducing total anxiety screening scores, and enhancing post-graduate and career preparedness for student-athletes. Although the overall scores for both depression and anxiety were on the low side of the scale, it was of great importance to evaluate individual constructs from each questionnaire. This provided insight as to what student-athletes were experiencing among those three different points in their life. As the findings showed, some percentages decreased from their first questionnaire to their third questionnaire.

Student-athletes reported that the biggest strengths of PROF Academy included "genuine advisors," "mock interviews," and "receiving critique on cover letters and résumés." When asked why they chose to participate in this program, responses included "to assist in transitioning from college to the work force," "it being a great way to connect with employers and receive critique on résumés," and "it would provide me with skills and practice for a career outside of college." These responses show the demand requested from collegiate student-athletes of this study to have resources available to them to assist in the next transition of their life. 
A unique aspect of this program included the alumni networking night. Not only did this teach student-athletes how to network, wear appropriate attire, eat in a professional manner, and communicate with individuals they just met, but it also served as a cornerstone of the program. Alumni who participated in this program were asked why they chose to attend. Some responses included: "I believe that giving back to the University that shaped me into who I am today. Also, to build positive relationships with student-athletes and advise them that there are always people willing to help guide them to better themselves," and "I value sharing my experiences with others. I had a very positive experience when I participated in athletics at Rowan and think the PROF Academy is a great program." When asked what they thought were some positive aspects of PROF Academy Networking Night, alumni responded, "Meeting student-athletes and program advisors. Having a sit down with different groups of people," and "The student-athletes asked me very engaging questions about my career and experiences. They were very focused on their athletics and academics."

This model can be adapted to other institutions at a low-cost point and utilize a college's own campus resources including the Athletics Department, Office of Career Advancement, Psychology Department, Health \& Exercise Science Department, and Wellness Center. Use of Rowan University's Office of Career Advancement by this population of student-athletes increased during each questionnaire collection. The overall benefit of this model is that it enhances the awareness of resources on campus for student-athletes as well as collaboration among departments on campus. If this model were to be implemented again, it would take place during the traditional academic calendar to enhance the retention rate of the student-athlete population. This is because the population number of our subjects decreased in September upon returning from summer break. The goal of replication serves to strengthen the results and further validate the findings in this study, allowing the program to evolve and become even more purposeful in the future.

\section{Limitations}

The main limitation to this study was the period of time in which participants were available. Conducting the study during spring semester, summer break, and fall semester resulted in difficulty in retention of participants. For instance, at the beginning of this program there were 39 student-athletes participating. After summer break the total dropped down to 17 student-athletes participating. If this study is conducted again, it is suggested to conduct it throughout a traditional academic calendar year. 


\section{Conclusion}

After completing this research project and analyzing data, it is clear to see the need present for assisting collegiate student-athletes with modalities to cope with mental health issues, including anxiety and depression. In addition, there was a strong benefit of enhancing awareness of resources on campus to assist with not only their mental health, but also career preparedness.

Continuing to provide opportunities for student-athletes to develop their identity, explore resources available to them, and learn modalities to enhance their well-being is apparent. Providing innovative programs, such as PROF Academy, serves to enhance the higher education experience by connecting athletics with additional resources on college campuses while keeping the main focus of providing a well-rounded experience for student-athletes. 


\section{References}

Bell, J., Prewitt, S., Bernhardt, V., \& Culpepper, D. (2018). The relationship between athlete identity and career exploration and engagement in division II athletes. International Journal of Exercise Science, 11(5). http://search.proquest.com/docview/2112206000/

Born, J. (2017). National protection of student-athlete mental health: The case for federal regulation over the National Collegiate Athletic Association. Indiana Law Journal, 92(3), 1221-1245.

Chew, K., \& Thompson, R. (2014). Mind, body and sport: Potential barriers to accessing mental health services. http://www.ncaa.org/health-and-safety/sport-science-institute/mind-bodyand-sport-potential-barriers-accessing-mental-health-services

Comeaux, E., \& Harrison, C. K. (2011). A conceptual model of academic success for studentathletes. Educational Research, 40(5), 235-245.

Davoren, A., \& Hwang, S. (2014). Mind, body and sport: Depression and anxiety prevalence in student-athletes. http://www.ncaa.org/health-and-safety/sport-science-institute/mindbody-and-sport-depression-and-anxiety-prevalence-student-athletes

Hoover, D. R., Jr. (2012). A balancing act: Division III student-athletes time demands and life roles (Order No. 3514840). Available from ProQuest Dissertations \& Theses Global. (1021917338).

http://ezproxy.rowan.edu/login?url=http://search.proquest.com/docview/1021917338?acc ountid $=13605$

Kroshus, E. (2015). Ask the expert: Transitioning from high school to college. http://www.ncaa.org/health-and-safety/sport-science-institute/ask-expert-transitioninghigh-school-college

Kroshus, E. (2016). Variability in institutional screening practices related to collegiate studentathlete mental health. Journal of Athletic Training (Allen Press), 51(5), 389-397. https://doi-org.ezproxy.rowan.edu/10.4085/1062-60050-51.5.07 
Lally, P., \& Kerr, G. (2005). The career planning, athletic identity, and student role identity of intercollegiate student athletes. Research Quarterly for Exercise and Sport, 76(3), 275285. https://doi.org/10.1080/02701367.2005.10599299

National Collegiate Athletic Association (NCAA) GOALS Study of the Student-Athlete Experience Initial Summary of Findings January $2016 . \quad$ (2016). http://www.ncaa.org/about/resources/research/ncaa-goals-study

Ryan, H., Gayles, J. G., \& Bell, L. (2018). Student-athletes and mental health experiences. New Directions for Student Services, 2018(163), 67-79. https://doiorg.ezproxy.rowan.edu/10.1002/ss.20271

Stroll, S. K. (1995). Moral reasoning of Division III and Division I athletes: Is there a difference? Paper presented at the Annual Meeting of the American Alliance of Health, Physical Education, Recreation, and Dance, Portland, Oregon. 